\title{
Discoveries: Old and New
}

Unrolling the Map: the Story of Exploration By Leonard Outhwaite. Pp. xiv +351 . (London : Constable and Co., Ltd., 1935.) 16s. net.

THE appearance of yet another history of exploration may be taken to indicate a popular demand for such works and, if one may judge from some of his remarks, Mr. Outhwaite writes primarily for the general reader. He disarms criticism by confessing that he does not "pretend to refinement in historical scholarship" and generously acknowledges help both from distinguished scholars and from previously published works. As he frankly admits, there is little originality in his book. Its facts are in the main accurate, but he seems to have found the limitations of space very hampering, and many parts of the later chapters are little more than notes on explorers grouped under a general heading, such as "Others in Africa". This limitation has other curious results, such as the inclusion of all the work of the Duke of the Abruzzi in the chapter on the Arctic, and the relegation of "mountain explorers" to an appendix to that chapter. These are perhaps mere faults of arrangement.

There are, however, two serious criticisms to make of this work. Its title suggests a progressive development of the knowledge of the world which is not in accordance with facts. Until quite recent times, there were too many 'secret' discoveries and too many national or personal jealousies to make it possible for anyone to say how much of the world was known at any one time. Mr. Outhwaite may know now-but explorers, like, say, Columbus on his fourth voyage, would have given a good deal to see a map of the world as it was known to their contemporaries.
Mr. Outhwaite further attempts to illustrate his ideas with a series of maps. It is not quite clear what these maps are intended to show, but if the general statement in the introduction is applicable to all maps then there are many serious errors in the book. On many of them the whole of Newfoundland is shown as 'known', whereas in fact inland journeys were practically unknown until relatively recent times. There is much more of the world 'known' in 1490 than there is when Vasco da Gama made his voyage to India. In some of the maps showing the exploration of Africa in the nineteenth century there are similar errors. In short, the map does not unroll itself in quite the way Mr. Outhwaite intended, and when, as sometimes happens, his own statements do not agree with the maps, the reader is left in confusion. Nor is he helped in his search for a solution by the bibliography, which in the main consists of "a few volumes that will tempt the fireside explorer". Some at least of the distinguished authors quoted would perhaps be a little suspicious of such comfortable púpularity.

It has been necessary to criticise Mr. Outhwaite's book partly because the publishers claim that it will be welcome to "students in need of a work of reference". It will, in fact, give them little help. On the other hand, the "schoolboy eager for one of the greatest true stories of adventure" and the "general reader" will find it, despite its awkward format, interesting, readable, and, up to a point, instructive. Even the student may study with profit the admirable drawings of ships, contributed by Mr. Gordon Grant, which combine art and scholarship in a manner which is much to be commended.

J. N. L. B.
Ornamental Shrubs and Trees: their Selection and Pruning

By Arthur J. Sweet. Edited by Walter P. Wright. Pp. xiii +64 . (London and Toronto: J. M. Dent and Sons, Ltd., 1935.) 5s. net.

OWNERS of gardens, large and small, will find this book very useful, for many people fail to get the best results from their shrubs and trees owing to their indifferent knowledge of pruning. All ornamental shrubs and trees do not need annual pruning; some give better results without it, others require an annual light thinning out of the older wood, and some respond most satisfactorily when the flowering branches are cut back each vear after the flowers are over and entirely new wood is relied upon for future flowers. Moreover, some shrubs and trees can be pruned when they are dormant in late autumn or winter, but if the same treatment were given to others the flowering wood for the following season would be cut out; that is why the autumnal clean up of gardens should not be made the time for the annual pruning of shrubs and trees.

In the book under notice all the little peculiarities of different shrubs, regarding pruning, are dealt with, and by the aid of descriptive lists and diagrams it need not be difficult for the most casual amateur to find out the proper time and most approved method for pruning his shrubs and trees. 